Paris-Jourdan Sciences Economiques

48, BD JOURDAN - E.N.S. - 75014 PARIS

TEL. : 33(0) 143136300 - FAX : $33(0) 143136310$

www.pse.ens.fr

WORKING PAPER N² 2006 - 32

Strategic weight within couples:

A microsimulation approach

Kristian Orsini

Amedeo Spadaro

JEL Codes : C70, D1, J16, H31

Keywords : individual strategic weight, microsimulation, tax-benefit systems 


\title{
Strategic weight within couples: a microsimulation approach
}

\section{Kristian Orsini ${ }^{1}$ and Amedeo Spadaro ${ }^{2}$}

\begin{abstract}
Individual strategic weight plays an important role in the intra-household allocation of resources; however, empirical studies invariably find such weight difficult to define in a plausible and computable way, given the available data. This paper proposes a framework for the calculation of household members' strategic weight that can be easily computed using a microsimulation model. The index proposed for each member as the share of resources the household would lose should he or she abandon it. The causes of strategic weight differentials are analysed in four EU countries with significantly different employment structure and tax-benefit systems (Finland, Germany, Italy and the United Kingdom), using EUROMOD, an integrated EU-15 microsimulation model.
\end{abstract}

Keywords: individual strategic weight, microsimulation, tax-benefit systems

JEL code: C70, D1, J16, H31.

\footnotetext{
${ }^{1}$ Center for Economic Studies, K U Leuven.

${ }^{2}$ Corresponding author. PSE Paris-Jourdan Sciences Economiques (Joint Research Unit CNRS-EHESS-ENPC-ENS) Paris, FEDEA Madrid and Department of Economics, Universitat de les Illes Balears, Ctra. Valldemossa km 7,5, 07122 Palma de Mallorca. E-mail: amedeo.spadaro@uib.es.
} 


\section{Introduction}

What advantage is there in individualising income tax or social benefits, as opposed to splitting or pooling them? Does it matter whether family and other personal circumstances are taken into account when calculating in-work benefits or tax credits? What are the likely consequences of each policy option in terms of personal income and welfare distribution, as opposed to household distribution? How does redistribution policy affect the household decision-making process and the welfare of individuals within families? With regard to reforms of the tax or redistribution system, much of the economic and political debate has focused on such questions in all European countries over the past three decades.

Economists have for long been ill-equipped to tackle these issues, insofar as they have become accustomed to treat households as if they were individuals, and to use household data in a similar fashion. The need to analyse policy impacts at an individual level forced researchers to propose alternatives to the unitary model, in order to explicitly take into account the existence of various decision-makers whose preferences quite likely differ.

One broad class of model represents multi-person household behaviour in a noncooperative framework $^{3}$. Such models show that if negotiation between spouses is viewed as a repeated game, noncooperative behaviour may occur if household members have divergent interests which cannot be reconciled. Contributions belonging to this family of models and inspired by the marriage market models of Becker (1974), such as those made by Grossbard-Shechtman (1984) or GrossbardShechtman and Neuman (1988), clearly show how strategic weight is related to individuals' relative income and conditions within the marriage market.

Other types of models start from the a priori assumption that spouses know each other's preferences well and that they exploit the gains to be had from cooperation during their long-term relationship as a couple ${ }^{4}$. The nature of the bargaining process is thus cooperative, and gametheoretic support (the Folk theorem) is provided for Pareto efficiency and appears to be a natural extension of the unitary setting. Models of this type focus on efficient intra-household outcomes by employing an explicitly axiomatic approach to bargaining solutions, such as Nash bargaining, and by specifying outside options for each individual in the household (Manser and Brown, 1980; McElroy and Horney, 1981, Haddad and Kanbur, 1994, Konrad and Lommerud, 2000 and Lundberg and Pollak, 1993).

A further type of model simply takes for granted that the equilibrium outcome is Pareto efficient, without taking into account any bargaining rules. This is the case of the collective model (Chiappori, 1988, 1992, Bourguignon et al. 1993) ${ }^{5}$ in which the spouses engage in a bargaining process which not only affects their behaviour, but also each spouse's wellbeing. The principal appeal of the collective model is that it provides a single framework for analysing the decisionmaking process and intra-household allocations, and economic behaviour and distribution are therefore analysed within a single and theoretically consistent framework. As a result, several empirical studies have explicitly adopted the collective framework to analyse the labour supply and

\footnotetext{
${ }^{3}$ See, for example, Leuthold (1968), Ashworth and Ulph (1981), Bourguignon (1984), Chen and Woolley (2001), Rubinstein (1982) and Binmore (1985). See Donni (2006) for an extensive review of non-cooperative models and their properties.

${ }^{4}$ Lundberg and Pollak (2003) have shown, however, that if current decisions affect spouses' future strategic weight, then inefficient outcomes are possible. For a discussion, see also Lundberg and Pollak (1994), Ott (1992) and Donni (2006).

${ }^{5}$ See Vermeulen (2002) for a complete survey.
} 
welfare distribution effects of reforms of the tax-benefit system ${ }^{6}$. The contribution made by these papers is significant, particularly in the field of welfare evaluation, where the unitary approach remains fundamentally unchallenged.

In both cooperative and noncooperative models, the difficulties in computing the strategic weights of each of the spouses continue to be the key issue. The lack of available data, theoretical restrictions and dependence on the tax-benefit schedule ${ }^{7}$ (which assigns a different implicit weight to each household member on the basis of various economic and socio-demographic characteristics) make it hard to define a criterion for computing strategic weight.

Without wishing to question the validity of the solutions proposed by various authors ${ }^{8}$ (which basically rely on estimation or calibration procedures), in this paper we propose an alternative, highly intuitive, approach; this is based on the hypothesis that each spouse's strategic weight is proportional to the share of resources lost by the household if he or she abandons it. The underlying rationale is that individual control over money is important for the decision-making process within the household and the subsequent distribution of resources and welfare; thus, a substantial body of literature suggests that an individual's strategic weight within the household is related to his/her contribution to its financial resources (see Browning et al. 1994, Phipps and Burton 1992, 1993 or Blumberg 1988).

The essential idea is similar to that contributed to game theory literature by Shapley (1953). His index (the Shapley value) captures the importance of adding a player to the winning coalition of a game (and thereby determining his strategic weight) ${ }^{9}$. Similarly, we propose an index aimed at capturing the strategic importance of each of the individuals in a given household by removing him or her from the coalition represented by the marriage.

However, this is not totally symmetric to the computation of the Shapley value, for several reasons. Firstly, even if we assume that household members play a cooperative game and that the surplus is shared in accordance with the index we propose, the outside options are not identical for those individuals entering a coalition (e.g. marrying) as for those leaving it (e.g. divorcing). Secondly, we do not construct any type of bargaining game (whether cooperative or noncooperative). We simply claim that this index may approximate the ex ante strategic weights in any "household game". For example, it can be used as a proxy of individual strategic weight for a policy evaluation exercise in a collective framework. It would therefore be possible, in a discrete labour supply model, to compute a set of alternative strategic weights and to use these variables as determinants of private consumption shares, without having to rely on a calibration method. Such an approach would be consistent with the view that a household member's strategic weight is an endogenous variable, partially determined by his or her behaviour (but also by the "caring" or "egoistic" preferences of the partner).

\footnotetext{
${ }^{6}$ See the special issue of the Review of Economics of the Household (Vol. 4, No. 2, June 2006) on the collective model and its application to the evaluation of tax reforms.

7 This last point is highly relevant to policy analysis. Several papers suggest a correlation between the tax-benefit system and the strategic weight. In Beblo et al. (2002), to cite merely one of these, the calibrated strategic weight is then regressed (together with other demographic variables) on the ratio of the earnings potentials of the spouses (i.e. the average disposable income when switching from 0 to 40 hours, given the alternative labour supply strategies available to the partner). The coefficients of the regression are then used to predict the strategic weight under alternative scenarios. A change in the tax-benefit system would in fact alter the earnings potentials and hence the strategic weight.

${ }^{8}$ On the contrary, we wish to stress the importance of conducting further research in these directions.

${ }^{9}$ The Shapley value has been also applied to the decomposition of inequality by Shorrocks (1999) and Sastre and Trannoy (2002).
} 
Additionally, and we believe this is our most important contribution, our index permits a comparative analysis of the performance of redistribution systems in equalising or disequalising the strategic weight of household members, both within and across countries. These two aspects have crucial implications with regard to evaluating redistribution policies. Interestingly, this index may also reveal social planners' preferences with respect to family policy and intra-household resource allocation.

The computation of this strategic weight index is based on microsimulation techniques, since it intrinsically relies on a counterfactual premise. Microsimulation models are powerful instruments whose analytical potential in the various fields of economic research have not yet been fully explored (Bourguignon and Spadaro, 2006). The advantage of using a microsimulation model lies in its capacity to fully describe the current economic situation, as well as potential counterfactuals, thereby capturing the complex effects of taxes and benefits.

The paper is devoted to the computation of the strategic weight of each household member. Specifically, we examine how strategic weight differentials depend on household characteristics, employment patterns (which to some extent reflect individual preferences) and the tax-benefit systems (which, by contrast, represent social preferences). To this end, we consider four European countries with profoundly different tax-benefit systems: Finland, Germany, Italy and the United Kingdom.

The paper is structured in the following way. Section 2 introduces our definition of household members' strategic weight. Section 3 describes the data selection and EUROMOD, the microsimulation model used to derive strategic weights. Section 4 presents some results regarding the attitude of social planners toward the family, as inferred from the tax-benefit system. Section 5 analyses strategic weight differentials, focusing in particular on the role of the labour market and of the tax-benefit systems. Section 6 presents the conclusions reached.

\section{Determining individual strategic weight}

In what follows, we assume that households simply because, for whatever reason, it is convenient for individuals to form them. Let us assume that no public good is at stake and that agents' behaviour is purely egoistic ${ }^{10}$; thus, they will form part of the household only as long as this continues to be a "convenient strategy". In other terms, household members will not accept "commanding" a share of resources lower than their marginal contribution to overall household welfare. The "strategic weight" of each individual within the household is hence determined by a hypothetical counterfactual, corresponding to the share of resources that would be lost if he or she were to "withdraw" from the household.

In formal terms, the weight of an individual $i$ may be defined as:

$$
\text { (1) } \lambda_{i}=\frac{Y D(n)-Y D(n-i)}{Y D(n)}
$$

where $Y D(n)$ and $Y D(n-i)$ represent household disposable income, with and without household member $i$. Logically, the strategic weight of an individual depends on two major factors: his/her own original income and the weight assigned to him/her by the tax-benefit system. Since disposable income may be divided into gross income $G Y()$ and net transfers $N T()$, we have that:

\footnotetext{
${ }^{10}$ We will discuss the implications of this strong hypothesis at the end of this section.
} 
(2) $\lambda_{i}=\frac{G Y(n)+N T(n)-(G Y(n-i)+N T(n-i))}{Y D(n)}$

or simply:

(3) $\lambda_{\mathrm{i}}=\mu_{\mathrm{i}}+\tau_{\mathrm{i}}$

where:

$$
\mu_{i}=\frac{G Y(n)-G Y(n-i)}{Y D(n)}
$$

(4)

$$
\tau_{i}=\frac{N T(n)-N T(n-i)}{Y D(n)}
$$

Normalising the indexes with respect to their sum permits a better comparison of the strategic weight of each household member relative to the others. Thus, the strategic weight of member $i$ can be computed as:

(5) $\bar{\lambda}_{i}=\frac{\lambda_{i}}{\sum_{k=1}^{n_{k}} \lambda_{k}}$

The following relation also holds:

(6) $\bar{\lambda}_{\mathrm{i}}=\bar{\mu}_{\mathrm{i}}+\bar{\tau}_{\mathrm{i}}$

where both right-hand-side terms have also been normalised with respect to $\sum_{\mathrm{k}=1}^{n_{k}} \lambda_{\mathrm{k}}$.

The earlier decomposition allows us to capture the weight that a tax-benefit system assigns to each household member, given their prevailing roles in society in terms of age and gender.

Alternatively, the proposed index can be employed as a mechanism for revealing social planners' preferences with regard to household formation. If the tax-benefit system is perfectly neutral with respect to household size, $\lambda_{i}$ can be reduced to the income share of person $i$ and $\Sigma \lambda_{i}=1$. Thus, $\Sigma \lambda_{i}$ $>1$ indicates a system which favours household formation, as the share of disposable income lost by the household if a member leaves exceeds his/her gross income, and vice versa for $\Sigma \lambda_{i}<1$. For confirmation, let us take the following example ${ }^{11}$ : the disposable income of each individual is (1$t) Y+b n^{a}$, where (1-t) $Y$ is the net income and $b n^{a}$ is a subsidy equal to $b$ times household size raised to $a$. Hence, assuming that all household members have the same net income:

(7) $\lambda_{i}=\frac{(1-t) Y+b\left[n^{a+1}-(n-1)^{a+1}\right]}{n\left[(1-t) Y+b n^{a}\right]}$

If $a=0$, then $\lambda_{i}=1 / n$, which corresponds to a neutral tax-benefit system. On the other hand, if the parameter $a$ is larger than 0 , the tax-benefit system favours, overall, household formation. We can therefore define the sum of the unstandardised $\lambda_{i}$ as a neutrality index; an index close to 1 means that the tax-benefit system approaches neutrality with respect to family size (and composition),

11 This example has been suggested by an anonymous referee who we are logically and unfortunately unable to acknowledge. 
while an index lower than 1 implies a tax-benefit system which discriminates against families. In turn, an index greater than 1 implies a pro-family tax-benefit system.

Obviously, the approach proposed has several shortcomings. The treatment of children, for example, is not fully satisfactory. The possibility of abandoning the household is an option available to adult household members, but not to children, especially younger ones; thus, it is not possible to compute the strategic weight of children. Further research should probably address the issue of how parents bargain over their children. The latter may be viewed as a type of public good into which both parents invest resources and subsequently bargain over their respective shares of the ensuing residual income. A priori, it seems likely that the parent who is most likely to obtain custody would in some way "incorporate" the children's strategic weight into his or her own weight. In the following analysis we will adopt this approach and assume that children will follow the mother in the case of her leaving the household ${ }^{12}$.

Secondly, we have not considered the possibility of behavioural reactions. When one member leaves the household, the other may decide to increase his/her labour supply; alternatively, the entry of a new member may cause a corresponding decrease. This hypothesis is extremely fragile, given that labour supply behaviour is a crucial element in the analysis of outside options. The explicit inclusion of behavioural reaction would require the definition of a full model of household members' labour supply and the game they play to allocate household resources. This would be extremely complicated and is beyond the scope of the present paper.

Thirdly, we ignore the role of alimony and child support, which is usually established by the courts or agreed between the spouses in the case of divorce. Once more, this decision is debatable, since in theory it means neglecting an important influence on the threat point of each household member. Unfortunately, however, such information is lacking in the microdatasets available.

Our intuition is that public goods, behavioural reactions and alimony legislation are all likely to reduce strategic weight differentials; the strategic weight we assume may therefore be considered as a special case of a more complex and realistic rule which takes the neglected factors mentioned above into account.

\section{Data selection and microsimulation software}

As explained in the previous section, the index is based on a counterfactual situation, represented by the effects upon disposable income of one of the household members leaving it (either alone or with the children). These counterfactuals are simulated using EUROMOD, an EU-wide integrated microsimulation model which permits the simulation of the tax system and most benefits unrelated to previous employment history (principally family benefits, housing allowances and income support $)^{13}$.

The present paper focuses on four EU countries, namely Finland, Germany, Italy and the UK; these were selected in order to permit us to analyse a sufficiently large variety of tax-benefit systems and social models, with different gender distributions of market and home production roles (see Esping Andersen 1990, 1999).

\footnotetext{
${ }^{12}$ Alternatively, children can be seen as a commitment mechanism. They have long-term implications, not least because they generate a liability to child support which is not modelled here in any way.

${ }^{13}$ For a detailed description of EUROMOD, see Sutherland (2001).
} 
Data for Finland are provided by the Income Distribution Survey, which contains a combination of register data and information gathered through interviews by Statistics Finland. The dataset refers to 1998 and contains detailed socioeconomic information for 25,010 individuals resident in 9,345 households. German data come from the German Socioeconomic Panel (GSOEP), established by the German Institute for Economic Research (DIW) in 1984. Unlike in Finland, only interviews are used to collect the annual data. The 1998 dataset supplies information regarding 18,772 individuals in 7,677 households. Italian data are collected every two years by the Survey of Household Income and Wealth (SHIW), conducted by the Bank of Italy. In this paper we use the 1995 dataset, which provides information about 23,924 individuals living in 8,135 households. Finally, data for the UK come from the Family Expenditure Survey, and are produced by the Office for National Statistics. It collects information for 15,586 individuals and 6,797 households over the period 1995-1996.

For each country, we selected a subsample of married and cohabiting adult couples (i.e. aged at least 18) with and without children, irrespective of their activity status. Children were defined as single persons aged under 30 and living with their parents. This very broad definition was intended to avoid the exclusion of a significant number of households with grown-up children in Italy. For the sake of simplicity, we excluded single parents and three-generation households. Table 1 shows the sample size, before and after this selection, for the four countries. The proportion of individuals in the sample subsequently included in the subsample varies from $71.6 \%$ in Italy to $59.9 \%$ in Finland, which is in fact the country with the greatest proportion of single households.

$<$ Table 1 about here $>$

Table 2 offers some descriptive statistics for the subsamples in the four countries considered. Since only heterosexual couples were selected, the number of females is identical to the number of males. Average age appears to be very similar across the panel, with females being approximately two years younger than their male partners. With regard to the proportion of males and females in employment, significant variation is apparent across the different "social models". Finland's male employment rate is almost $10 \%$ higher than that for Italy and the UK. However, it is in the female employment rate that differences are most striking: in Finland the rate of female employment is almost twice than that of Italy, while Germany and the UK occupy an intermediate position. It should be remembered that the above data refer to a period from the mid- to late $90 \mathrm{~s}$, and that female employment rates have significantly increased in recent years in all countries except Finland. Regarding household typologies, it is noticeable that childless households are the dominant household form in all countries except Italy ${ }^{14}$. Indeed, Italy is characterised by a particularly high incidence of households with grown-up children. Finland, Germany and the UK have similar shares of households with one and two children. Finland and Italy, moreover, have a significant proportion of households with three or more children (above 11\%).

$<$ Table 2 about here $>$

\section{Social preferences and the neutrality index}

Before examining the distribution of strategic weight per se, it is interesting to analyse the distribution of the neutrality index, as defined in Section 2. Thus, the tax-benefit system awards a "family bonus" when the neutrality index is greater than 1, but applies a "family penalty" when this figure is lower than 1 . In the first case the tax-benefit system is obviously "pro-family", whereas in the second case it is "anti-family".

\footnotetext{
${ }^{14}$ It should be noted that childless households could be comprised by younger couples, as well as older couples whos children have already left the household.
} 
Table 3 shows the average neutrality index: with respect to the four household typologies analysed (i.e. couples without children, couples with one child, couples with two children and couples with three or more children), Italy dominates Finland, which in turn dominates the UK, which in turn dominates Germany. Italy is in fact the only country which appears to have a slightly pro-family tax-benefit system. In the case of households with 3 or more children, the sum of the strategic weight is .739 for Germany, .845 for the UK, .889 for Finland and 1.077 for Italy. For couples without children the differences are slightly more contained, and the tax-benefit system approaches neutrality. Germany and the UK are again the two systems which are furthest from neutrality (.936 and .945 respectively), while Finland and Italy are closer (in absolute value) to neutrality: the sum of strategic weight is 1.022 for Italy and .958 for Finland. The magnitude of the family "penalty" therefore increases with household size; it is greatest for households with numerous children and lowest for childless households. Italy displays the opposite trend, as households with numerous children apparently receive a larger family "bonus” than households with few children.

\section{$<$ Table 3 about here $>$}

Obviously, differences in the neutrality index do not only result from the tax-benefit system, but may well be produced by demographic factors or differences in employment levels. Therefore, the information contained in Table 3 is further disaggregated in Table 4. In the latter, we focus exclusively on working-age households and disaggregate the previous figures by female employment status (i.e. in employment or not in employment), arguably one of the most significant factors affecting gender-based strategic weight differences. Germany still appears to have the most anti-family tax-benefit system. In particular, the family "penalty" appears to be extremely consistent in households with children where the mother is not in employment. Finland and the UK display identical features, while Italy is again an outlier having slightly pro-family tax-benefit system. Family "neutrality" is observed for childless couples in which the female is in employment: Italy and the UK approach unity, while Germany and Finland continue to penalise such couples.

One last issue, of great political and also policy relevance, is how the level of the penalty or bonus varies as a function of income. Figure 1 shows the sum of female and male strategic weights as a function of disposable income. Interestingly, all the systems studied tend towards neutrality as income increases. In Finland, Germany and the UK, however, the approach is bottom-up: at lower income levels the tax-benefit system produces a higher family penalty, which is reduced as income increases. The size of the penalty, moreover, is higher in the case of households with children. This situation could be interpreted as providing support for the somewhat conservative view that the welfare state (in particular, income support) encourages family disruption and lone motherhood and therefore contributes to social instability.

\section{$<$ Figure 1 about here $>$}

However, what does the anti-family or pro-family nature of the tax-benefit system imply in terms of the strategic weight of the household members? Are the benefits of the family "bonus" equally shared, or does the system award extra strategic weight to one of the household members? In other words: does increasing family as a whole necessarily mean increasing the welfare of each member? Furthermore, which elements of the tax-benefit system affect the distribution of strategic weights? These questions will be discussed in the following section.

\section{Strategic weight}


In the following analysis, individual strategic weights have been standardised with respect to their total value, as defined in equation (5). This facilitates comparison not only across household members, but also across countries.

The average male-female strategic weight differential appears to be lowest in Germany and highest in Italy (the normalised strategic weight for females and males is .506 and 0.494, respectively, in Germany, compared to 0.354 and 0.646 in Italy). The case of Italy is broadly in line with our expectations, given the differential in male and female employment rates and, therefore, in access to primary income. The results are more surprising for Germany. Male employment rates are similar in Germany and the UK, whereas the British female employment rate is higher than the German one. Nevertheless, the relative strategic weight for German females (.506) is always higher than that for British women (.406), and even their Finnish counterparts (.471), despite the fact that the latter have significantly higher employment rates.

Table 4 shows the normalised average strategic weight for females and males, disaggregated for households with children and households with one, two and three or more children. It is immediately apparent that the strategic weight of females without children is quite similar in Germany, the UK and even Italy (varying from .344 to .369). In households with children, however, the pattern is extremely different. Having one, two or three or more children raises the strategic weight of German mothers to .484, .547 and .674, respectively. In these countries, it is clear that other aspects of the system play a role at least as important as the employment rate in explaining gender-based strategic weight differentials. At the opposite extreme is Italy, where the presence of children does not appear to be an influence, while Finland and the UK are located between these two extremes.

\section{$<$ Table 4 about here $>$}

Average strategic weight differentials, however, tend to be somewhat uninformative, given the fundamental heterogeneity of employment statuses and earning capacities in the households sampled. An interesting question concerns the pattern of strategic weight differentials with respect to total income. Figures 2 and 3 show, respectively, the pattern of strategic weights, by household disposable income, in households without and with children. For couples without children the profile is remarkably flat; this is surprising, as the share of female employment may be expected to rise in line with increasing disposable income. Germany and the UK display a very similar pattern; the strategic weight of males is always between .6 and .7, while that of females ranges from .3 to .4. In Finland the gender-based strategic weight differential is far more contained (approximately .45 for females and .55 for males), although this gap widens in the higher income deciles. Italy, on the other hand, displays a highly atypical pattern: the strategic weight for females is initially very low (.27 in the first income decile), then increases in the second and third decile, to fall again in the fourth decile. Finally, from the fifth decile onwards it increases more or less linearly. Within the higher income deciles, however, the gender-based strategic weight gap approaches the levels of the other countries studied.

$<$ Figure 2 about here $>$

When observing couples with children, inter-country differences become more evident. Finland, Germany and the UK show a typical X pattern: in the lower deciles, mothers have a higher strategic weight, which is then progressively reduced, while the strategic weight of fathers increases symmetrically over the whole range. What does vary across the countries observed is the crossing 
point i.e. the point where fathers' strategic weight surpasses that of mothers. In the UK this occurs in the second decile, in Finland in the fifth decile and in Germany in the seventh decile. In general, the differences appear to be largely contained, even more so than in the case of households without children. This evidence suggests that the tax-benefit system more than compensates for the lower employment rate typically experienced by mothers (with the exception of Finland, where the employment rate gap of mothers tends to be less extreme).

Two features are worthy of comment: the extremely high strategic weight of mothers in the lowest decile in Germany, and the heterogeneous pattern of strategic weight differentials in Italy. The first is probably a result of the generous income support benefits for lone mothers. In the second, the pattern is once more somewhat difficult to explain, but may be related to the specific characteristics (e.g. age or labour market participation) of households in the different income deciles.

$<$ Figure 3 about here $>$

A priori, demographic variables, labour market participation and the tax-benefit system all contribute to shaping the pattern of strategic weights. In order to more accurately separate the role of market and state institutions in determining strategic weight differentials, it is useful (for households of working age only) to look at the influence of female employment status upon strategic weight differentials. Obviously, differences in male employment rates are also significant, but these tend to principally affect retirement behaviour; within primary working age, male employment rates are quite similar. In the following analysis we therefore concentrate on the crucial role of female employment.

\subsection{Female employment}

Table 5 shows the standardised strategic weight for females and males of working age (20 to 60), disaggregating this information by the employment status of the female partner. It is immediately noticeable that, in general, the gender-based strategic weight gap for childless couples in which the female works tends on average to be both quite small and fairly similar across countries, ranging from .434 (United Kingdom) to .475 (Italy). The lower strategic weight of working female spouses is probably due to gender differences in working hours as well as in hourly wages, which still penalise women.

However, in childless households in which female partners do not work, their strategic weight falls to 0.183 in Italy, .215 in the United Kingdom, .288 in Germany and .362 in Finland. These differences across countries are not only a result of the various tax-benefit systems: some of the greater strategic weight enjoyed by, for example, Finnish women could reflect their earlier entry into the labour market and, consequently, access to contributory benefits (particularly pensions).

In households with children, on the other hand, even if the female partner does not work, the differential between the strategic weight of the male and female partners is much narrower, mainly due to the tax and benefit entitlements children generate. The greatest strategic weight once more corresponds to Italian males (.759), whereas in Germany the index for mothers outweighs that of fathers even when the former do not work (.522 and .478 for females and males, respectively). The UK and Finland occupy an intermediate position.

In the case of working mothers, the gap is even narrower than that for childless couples. Here, the additional strategic weight produced by children (which we assign to mothers) makes the distribution almost egalitarian. In Germany, the strategic weight of mothers again outweighs that of fathers, but in the remaining countries the figure falls fractionally short of .5. 


\section{$<$ Table 5 about here $>$}

It can thus be observed that amongst working-age couples in which the female partner is in employment, the distribution of strategic weight tends to be quite egalitarian. This does not mean that the tax-benefit system plays an insignificant role: it may well compensate for shorter average working hours and lower average wages among mothers. The impact of net transfers is therefore equally important for non-working age families, working-age families in which the mother is in employment and working-age families in which the female does not work. In the next section we will specifically address the issue of net public transfers.

\subsection{Net public transfers}

Using the framework established above, normalised strategic weights may be decomposed, for both males and females, into a market component (original income) and a public transfers component (net transfers) ${ }^{15}$. Table 6 presents this decomposition for the four countries studied.

\section{<Table 6 about here>}

Italy is remarkable for the significant role of net transfers in defining strategic weights within childless households. This is unsurprising: as children tend to stay longer with their families than in the rest of Europe, and family formation tends to be considerably delayed, childless households are on average older than in the other European countries considered, and thus they display a higher share of transfers related to old age. Net transfers here are positive (on average) for both female and male spouses, although the size of the transfer tends to reinforce the strategic weight differential of original income. Again, this was foreseeable: since retirement benefits are employment-related, they tend to reproduce strategic weight differential patterns similar to those generated by original income. This also appears to be the case in Finland, while in Germany and the UK net transfers tend to have a very small average effect. At least for the UK, this could be partially explained by the fact that the primary source of income for many retired people lies in private rather than public pensions, and thus reflects original income.

Net transfers also tend to be negative for families with children. The different age structure of households with and without children is likely to have an influence, since adults in households with children tend to be active in the labour market. Germany is noticeable for the significant role of net transfers in determining strategic weight; in particular, it appears that taxes strongly reduce the relative strategic weight of males and increase that of females. At the other extreme is Italy, where public transfers apparently play only a marginal role in the case of households with children, and relative strategic weight is basically determined by market incomes. This is also consistent with the Italian welfare state model, which is strongly biased towards pensions, with only minor childrelated benefits and income support schemes. Only in households with three or more children is the strategic weight of mothers increased through the tax-benefit system. The United Kingdom and Finland, on the other hand, display similar patterns for households with children: in both cases transfers reduce the relative strategic weight of males to increase that of. Once again, this is probably due to the interaction between employment and earning differentials and progressive taxation.

\footnotetext{
${ }^{15}$ Replacement incomes in this case have been treated as net transfers; arguably, however, they could be considered as deferred wages.
} 
As in the previous section, it is possible to analyse the role of transfers and original income across income deciles. Figures 4 and 5 show the profile of strategic weights, by income decile, before and after public transfers to households without and with children, respectively.

$<$ Figure 4 about here $>$

$<$ Figure 5 about here $>$

For each decile, strategic weight has been decomposed into market and net transfer components. The figures show how strategic weight is modified by net transfers: the dotted line represents strategic weight calculated using gross income, whereas the solid line represents strategic weight calculated using disposable income i.e. gross income plus net public transfers. An examination of Figure 4 reveals that the pattern is quite similar across countries i.e. public transfers "harmonise" strategic weight. Strategic weight calculated using gross incomes tends to increase with income decile, while public transfers increase strategic weight differentials in lower deciles and reduce them in upper deciles. The decile in which the effect changes varies across countries: in Italy, for example, net transfers are positive for both men and women up to the ninth decile; this household typology is on average older than its counterparts in the other countries analysed. In the UK, on the other hand, the effect is reversed in the fifth and sixth deciles, probably due to the lesser role of public old age benefits. In Finland and Germany the switch occurs between the sixth and the eighth decile. From a gender-based perspective, net public transfers have an ambiguous effect. As Table 6 shows, strategic weight is increased for both males and females, although (except in the UK) the increase is greater for the former, in both absolute and relative terms. The decile patterns show that net public transfers constantly increase strategic weight differentials based on original income in Finland and in Germany. Original labour market differences are thus duplicated through employment-related benefits. In the case of Italy, however, net transfers tend to increase strategic weight differentials based on original income in the very bottom and top deciles. In the UK, by contrast, net transfers reduce gender-based strategic weight differentials in the two lowest income deciles and increase them in the rest of the distribution.

Figure 5 depicts a similar pattern to Figure 4, with some exceptions. For males in Finland and Germany, net public transfers decrease, on average, their strategic weight over the whole income range. The same applies to the UK, starting from the second income decile (in the first income decile positive net transfers still have a positive effect on the strategic weight of males). The extent of the reduction is considerable in Germany and the UK, especially in the lowest deciles. This is probably related to the generous income assistance available for single-earner households; if based solely on original income, males would have an extremely high strategic weight. However, access to income support and generous supplements for children reduces the loss of income that the household would experience if the male partner were to leave. In Finland and Italy the reduction in males' strategic weight is much lower. In Finland this is mainly due to the presence of a second earner in the household, while in the case of Italy, the lack of a safety net reduces the equilibrating effect of public transfers upon strategic weight. This also explains why the strategic weight for males is considerably higher in the lowest deciles (i.e. in the part of the distribution characterised by lower female employment rates).

With respect to childless couples, the effect of transfers switches from positive to negative earlier in the distribution. This is once more due to the different age structure of households with children. The presence of children also explains why strategic weight is so markedly increased by public transfers: lone mothers have access to significantly greater income resources than single males (although of course their needs are much greater). This explains why in the lowest income deciles the strategic weight of females is raised above that of males. 
In the following section we will attempt to confirm the explanations offered above by examining the effect of each transfer component separately.

\subsection{Decomposing net transfers}

In this section we will explore in detail how various instruments contained in tax-benefit systems affect intra-household strategic weight differentials, making intensive use of the microsimulation model. Instruments have been classified into broad groups: (i) taxes and social security contributions (ii) income support and housing benefits (iii) family benefits (iv) old age and sickness benefits and (v) unemployment benefits. For each group of measures we simulate the strategic weight that would result if these did not exist; this allows us to estimate the specific contribution of each element of the tax-benefit system. The analysis is, once more, performed for households both with and without children.

Tables 7 and 8 display the difference between the baseline strategic weight and the strategic weight resulting from the removal of the specific instrument. The results are again disaggregated for households with and without children. Different fonts have been used for the figures to facilitate their reading; this makes immediately clear which instruments play a significant role in reshaping intra-household strategic weight differentials.

$<$ Table 7 about here $>$

$<$ Table 8 about here $>$

For childless families, the situation is relatively simple; since such households tend, on average, to be older the main benefits they receive are pensions, and thus the tax system has only a marginal influence upon strategic weight, particularly in the case of Finland. When it does play a significant role it is the female partner who is principally favoured. In both Germany and in Italy, the existence of family-based provisions in the tax system (e.g. joint taxation or deductions for dependent spouses) tends to increase the income loss that the household would experience if the female spouse were to leave, although this effect is rather modest.

Income support and housing benefits, by contrast, are important. Their effect is to reduce the income loss that female partners would suffer if their male partners were to leave the household (in Germany and the UK) or, alternatively, to reduce the income to which employed partners (in this case male) having a dependent spouse or child are entitled. As all such benefits are means-tested, their effect is strongest in lower income deciles; in higher income deciles, as female partners have access to private sources of income (from either current or previous employment) they are ineligible for means-tested benefits.

Finally, public pension systems tend to reproduce inequalities in access to private sources of income produced throughout working life. Since childless households are mainly older households, retirement income has a strong influence upon strategic weights. This effect of pensions is particularly strong in Italy, given the old age bias of the Italian welfare system. The same is true (to a lesser extent) in Germany. In the UK, public pensions mainly affect the lower income deciles, since higher income households have largely opted out of the state system in order to join private pension schemes. Finally, the effect of pensions on the strategic weight of males and females in Finland appears to be much less biased than in the other countries. This is mainly due to the combination of a flat rate universal old age allowance, coupled with the historically high participation of females in the labour market. 
In households with children the situation is much more complex, and here the tax system plays an important role. In Germany, the prevailing joint tax system, characterised by significant tax deductions for dependent children (for higher income groups), significantly increases the strategic weight of the female partner. This effect is highest in the second income decile and decreases progressively as household income (and the income of the female partner) increases. The Italian and British tax systems are basically individualised, but elements of family-based taxation remain in the case of the child tax credit and in the deductions for married couples (dependent spouse). In the UK there also exists a special tax credit for lone parents. These elements tend to increase the strategic weight of the female spouse. As the income of mothers increases, however, the tax advantages (i.e. deductions for dependent spouse) for couples with children either disappear or become relatively less important. Finally, although the tax system in Finland is totally individualised, it nevertheless reduces the strategic weight of male partners, especially in the lowest income decile. This is mainly due to the fact that taxation reduces the weight of the private resources of male spouses to the “advantage” of non-working females.

Housing benefits and social assistance (as income support) are particularly important in the case of households with children. Most income support schemes, in fact, include fairly generous childrelated supplements as well as special allowances for lone parents. The most generous income support scheme is clearly the German one. The Finnish benefit system is also quite generous, but the number of recipients (as well as the size of the transfer) is smaller, given the higher employment rates for both males and females. In the case of the UK, we have included Family Credit (a tax credit) within aggregate income support and housing benefit: this explains why the effect of these instruments tends to be significant in all income deciles. Finally, Italy lacks a well-developed system of income support; employed workers are entitled to social transfers if their wages are below a certain threshold, but the effect of this scheme is extremely limited.

A similar scheme also provides income supplements to employed parents of dependent children. These child benefits are quite strictly means-tested and their effect is significant only in the lower income deciles. Family income support is also means-tested in the case of Germany, and higher income groups usually prefer the more favourable tax deduction scheme.

In Finland and in the UK, on the other hand, child benefit is universal, although its impact is moderate over the whole range of the distribution. What seems a priori illogical is the negative effect on women's strategic weight of removing family benefits in the lowest income deciles. This is in fact largely explained by interactions between the tax and benefit systems i.e. cutting off child benefit leads to increased housing benefit and income support.

The above also demonstrates the limitations of our approach: in highly complex welfare states it is impossible to measure the precise impact of a specific instrument, especially since every instrument has been designed taking into account the other instruments which exist in the tax-benefit system. However, this paper by no means attempts to measure the overall impact of this system upon the individual strategic weight of spouses; instead, the aim is simply to demonstrate the diverse effects of particular elements of the tax-benefit system upon the strategic weight of partners within a family.

\section{Conclusions}

Employing a highly intuitive concept of intra-household strategic weight, based on microsimulation techniques, we have computed the strategic weight of each spouse and examined its dependence on 
the tax-benefit system in four European countries between which that system differs greatly. The results show that these differences play an important role in determining such strategic weights. We believe our proposed index may be of great utility in the empirical evaluation of redistribution systems, as we have shown. Naturally, we understand and accept the limitations discussed in Section 2. For example, the framework adopted is completely static; that is to say, when calculating the strategic weight of one of the partners, we did not consider the possibility that the other partner may adjust his/her behaviour in the labour market, and nor did we consider the role of household production or of public goods. Moreover, the decision to "assign" children to mothers may be questionable. Traditionally, however, children are assigned to female spouses on the basis of socially dominant gender roles, and women's "control” over children may well compensate for their lower strategic weight with sole regard to income (Lundberg and Pollak, 1993). It is important to note, however, that strategic weight should not be interpreted as a sharing rule, but instead as simply one factor among several which may affect the intra-household distribution of part or all of its resources. With regard to a sharing rule, it would be reasonable to assume that part of total household income is used to purchase non-private goods and services, and that only a residual share is allocated in accordance with strategic weight differentials (see Chen and Wolley 2001).

Bearing such limitations in mind, our approach provides further clarification of how social and individual preferences interact to determine strategic weight within the household, and of the distribution of strategic weight differentials.

Individual preferences principally affect individuals' labour supply strategies, which play a significant role in determining earning capacity and, consequently, strategic weight differentials. However, differences in male and female employment rates are only one of the factors affecting strategic weights within a couple. Net transfers, both positive and negative, also play a significant role in reshaping strategic weight differentials. While some measures are largely neutral, others tend to reduce existing inequalities or exacerbate intra-household strategic weight differentials.

On this point, it is interesting to note that a pro-family tax-benefit system might have ambiguous effects on the welfare of individuals within the family. If such a system is intended to reduce the outside options of the "weak" partner, the effect on the individuals within the household might be far from desirable. This is particularly evident in the Italian case: the pro-family system implicitly encourages family formation and preservation, but does so at the cost of reducing the strategic weight of the weak partner.

At the other extreme is Germany, whose system unexpectedly appears to penalise family stability. However, the policies which reduce incentives for family preservation simultaneously produce a more equitable distribution of strategic weight, and possibly of resources.

This effect is particularly important for the lowest deciles, where strategic weight differentials are most important and where the unequal distribution of resources (influenced by the unequal strategic weights of the partners) may perversely affect individual welfare, producing poor individuals within non-poor families, for example. However, it is also in the lowest income deciles where public policies may significantly adjust strategic weights. In higher income deciles the strategic weight of spouses tends to be far more equal; individual preferences (and the distribution of human capital and talents) are the principal factors shaping strategic weight differentials in higher income groups. The marginal role of public policies is also demonstrated by the fact that the distribution of strategic weight is similar within highly diverse institutional situations.

The index presented in this paper may therefore be employed as a straightforward tool to analyse the impact of tax-benefit systems on relative strategic weight, to compare their effect across 
countries and to assess the impact of tax-benefit reforms which may affect differently the strategic weight of individuals within the household.

More ambitiously, this index could be used as a starting point for the elaboration of a more realistic sharing rule i.e. one which takes into account dynamic strategies e.g. individual responses to the threat of family breakup, as Rubinstein (1982) remarks, adult control over younger children and economies of scale in the purchase of public goods and services.

Empirically, it would be interesting to discover if there exist natural experiments within countries which could be used to validate the index proposed here or if empirical regularities may be found to suggest that couples in which, say, the female's strategic weight is high, adapt their behaviour, and that such changes are to be expected. This and other related topics must, however, be left for future research.

Acknowledgements: This is a completely revised version of the paper "Sharing resources within the household: a multi-country microsimulation analysis of the determinants of intra-household "strategic weight" differentials and their distributional outcomes", PSE Working Paper No. 200504.

We are grateful to Vincenzo Atella, Dani Cardona, André Decoster, Jacques Lecacheux, Holly Sutherland and Luc Gladiateur for in-depth comments. We are indebted to four anonymous referees for their useful comments. All errors or omissions are entirely the responsibility of the authors. This paper was written as part of the MICRESA (Micro Analysis of the European Social Agenda) project, financed by the Improving Human Potential programme of the European Commission (SERD-2001-00099). For the countries considered in this paper, EUROMOD relies on the following microdata: the Income Distribution Survey supplied by Statistics Finland; the German Socio-Economic Panel Study made available by DIW; the Survey of Household Income and Wealth, provided by the Bank of Italy; and the Family Expenditure Survey, supplied by the British Office for National Statistics. We are indebted to our present and former colleagues of the EUROMOD team. Amedeo Spadaro gratefully acknowledges financial support from the Spanish Government- MCYT, (SEJ2005-08783-C04-03).

\section{References}

Alderman, H., Chiappori, P.-A., Haddad, L., Hoddinott, J. and Kanbur R. (1995), "Unitary Versus Collective Models of the Household: Is It Time to Shift The Burden of Proof ?", World Bank Research Observer, 10, pp. 1-19.

Ashworth, J. and Ulph, D. (1981), "Household Models", in Charles, B. (ed.), Taxation and labour supply, (pp. 117-133). London: Allen and Unwin.

Beblo, M., Beninger, D. and Laisney, F. (2003), "Family Tax Splitting: A Microsimulation of its Potential Labour Supply and Intra-household Welfare Effects in Germany", ZEW Discussion Paper, No. 03-32, Manheim.

Becker, G. (1974), "A Theory of Marriage: Part II", The Journal of Political Economy, 82, pp. S11S26.

Behrman, J. R. (2003), "Intrahousehold Distribution and the Family", in Rosenzweig, M. R. and Stark, O. (eds.), Handbook of Population and Family Economics, Vol. 1A, pp. 125-187, North Holland, Amsterdam.

Binmore, K., (1985) "Bargaining and Coalitions” in Roth, A. (eds.), Game-theoretic Models of Bargaining, Cambridge, CUP, pp. 259-304.

Blumber, R.L. (1988), “Income Under Female Versus Male Control: Hypotheses From a Theory of Gender Stratification and Data From the Third World”, Journal of Family Issues 9(1), 51-84.

Blundell, R. (1988), "Consumer Behaviour: Theory and Empirical Evidence - A survey", Economic Journal, 98, pp. 16-65. 
Blundell, R. and Meghir, C., (1986), "Selection Criteria for a Microeconometric Model of Labour Supply", Journal of Applied Econometrics, 1, pp. 55-80.

Blundell, R. and Walker, I. (1986), "A Life-cycle Consistent Empirical Model of Family Labour Supply Using Cross-Section Data", Review of Economic Studies, 53, pp. 539-58.

Bourguignon, F. (1984), "Rationalité individuelle ou rationalité stratégique: le cas de l'offre familiale de travail", Revue économique, No. 1, January, pp. 147-62.

Bourguignon, F. and Chiappori, P-A. (1992), "Collective Models of Household Behavior", European Economic Review, 36, pp. 355-64.

Bourguignon, F. and Spadaro, A., (2006), "Microsimulation as a Tool for Evaluating Redistribution Policies”, Journal of Economic Inequality, Vol.4, No. 1, pp. 77-106.

Bourguignon, F., Browning, M., Chiappori, P-A. and Lechène, V. (1993), "Intrahousehold Allocation of Consumption: Some Evidence on French Data", Annales d'Economie et Statistique, 29, pp. 137-156.

Browning, M., Bourguignon, F., Chiappori, P.-A. and Lechène V. (1994), "Income and Outcomes: A Structural Model of Intrahousehold Allocation”, The Journal of Political Economy, 102, No. 6, December, pp. 1067-1096.

Chen, Z and Wolley, F. (2001), "A Cournot-Nash Model of Family Decision Making", The Economic Journal, 111, October, pp. 722-748.

Chiappori, P.-A. (1988), "Rational Household Labor Supply", Econometrica, 56, January, pp. 6389.

Chiappori, P.-A. (1992), "Collective Labor Supply and Welfare", The Journal of Political Economy, 100, June, pp. 437-467.

Donni, O. (2006), "Modèles Non-Coopératifs d’Offre Familiale de Travail". L’Actualité Economique. (forthcoming)

Esping-Andersen, G. (1990), “The Three Worlds of Welfare Capitalism”, Princeton, NJ: Princeton University Press.

Esping-Andersen, G. (1999), “Social Foundations of Postindustrial Economies”, New York: Oxford University Press.

Fortin, B. and Lacroix, G. (1997), "A Test of the Unitary and Collective Models of Household Labour Supply", Economic Journal, 107, pp. 933-55.

Grossbard-Shechtman, A. (1984) "A Theory of Allocation of Time in Markets for Labor and Marriage”, Economic Journal, 94, 863-882.

Grossbard-Shechtman and Neuman, S. (1988) "Women's Labor Supply and Marital Choice”, Journal of Political Economy, 96, 1294-1302.

Haddad, L. and Kanbur, R. (1994) “Are Better-off Households More Unequal or Less Unequal”, Oxford Economic Papers, 46, 445-458.

Konrad, K. and Lommerud, K. (2000) “The Bargaining Family Revisited”, Canadian Journal of Economics, 33, 471-487.

Leuthold, J., (1968) “An Empirical Study of Formula Income Transfers and the Work Decision of the Poor", Journal of Human Resources, 3, 312-323.

Lundberg, S. and Pollak, R. (1993), "Separate Spheres Bargaining and the Marriage Market", The Journal of Political Economy, 101, December, pp. 988-1010.

Lundberg, S. and Pollak, R. (1994), "Noncooperative Bargaining Models of Marriage”, The American Economic Review, 84, No. 2, May, pp. 132-137.

Lundberg. S. and Pollak, R. (2003), "Efficiency in Marriage", Review of Economics of the Household, 1, 153-167.

Manser, M. and Brown, M. (1980), "Marriage and Household Decision-Making: A Bargaining Analysis", International Economic Review, 21, pp. 31-44.

McElroy, M. and Horney, M. (1981), "Nash-Bargained Household Decisions: Towards a Generalisation of the Theory of Demand", International Economic Review, 22, pp. 333-49. 
Ott, N. (1992) “Intrafamily Bargaining and Household Decisions”, Berlin/Heidelberg: SpringerVerlag.

Phipps, S. and Burton, P. (1992), "What is Mine is Yours? The Influence of Male and Female Income on Patterns of Household Expenditure", Discussion Paper 92-12, Department of Economics, Dalhousie University.

Phipps, S. and Burton, P. (1993), "Collective Models of Household Behaviour: Implications for Economics Policy”, Paper presented at the Status of Women Economic Equality Workshop, Ottawa, 29-30 November.

Rubinstein, A. (1982) "Perfect Equilibrium in a Bargaining Model”, Econometrica, Vol. 50, pp. 97109.

Samuelson, P. (1956), "Social Indifference Curves", Quarterly Journal of Economics, 70, pp. 1-22.

Sastre, M. and Trannoy, A. (2002), "Shapley inequality decomposition by factor components: some methodological issues" published in Moyes, P., Seidl, C. and Shorrocks, A. (2002).

Schultz, T.P. (1990), "Testing the Neoclassical Model of Labor Supply and Fertility", Journal of Human Resources, 25, pp. 599-364.

Shapley, L. S. (1953) "A Value for n-Person Games" in Kuhn H. W. and Tucker A. W. (eds.), Contributions to the Theory of Games, Vol. II, pp. 307-17, Princeton University Press, Princeton.

Shorrocks, A.F. (1999). Decomposition procedures for distributional analysis: a unified framework based on the Shapley value. Unpublished paper, University of Essex.

Sutherland, H. (2001), "Final report EUROMOD: an integrated European tax-benefit model", EUROMOD working paper EM9/01.

Thomas, D. (1990), "Intra-household Resource Allocation: an Inferential Approach", Journal of Human Resources, 25, pp. 635-664.

Vermeulen, F. (2002), "Collective Household Models: Principles and Main Results", Journal of Economic Surveys, 16, 533-564. 


\section{Tables and figures}

Table 1: Weighted sample before and after selection

\begin{tabular}{lcccc}
\hline Before selection & Finland & Germany & Italy & UK \\
\hline \# of individuals & $5,086,139$ & $78,956,258$ & $57,206,842$ & $57,443,762$ \\
\# of households & $2,355,000$ & $32,289,963$ & $19,816,115$ & $24,490,138$ \\
& & & & \\
After selection & & & & \\
\# of individuals & $3,046,674$ & $57,934,344$ & $40,976,950$ & $39,245,363$ \\
\# of households & 992,192 & $19,507,731$ & $12,470,477$ & $13,304,952$ \\
& & & & \\
Share of total sample & & & & \\
individuals & 59.9 & 73.4 & 71.6 & 68.3 \\
households & 42.1 & 60.4 & 62.9 & 54.3 \\
\hline \hline
\end{tabular}

Source: Authors' calculations, based on EUROMOD

Table 2: Descriptive statistics (weighted)

\begin{tabular}{|c|c|c|c|c|c|c|c|c|}
\hline & \multicolumn{2}{|c|}{ Finland } & \multicolumn{2}{|c|}{ Germany } & \multicolumn{2}{|c|}{ Italy } & \multicolumn{2}{|c|}{ UK } \\
\hline & Males & Females & Males & Females & Males & Females & Males & Females \\
\hline \# of adult individuals & 989,338 & 989,338 & $17,487,514$ & $17,481,694$ & $12,467,897$ & $12,467,897$ & $13,303,374$ & $13,303,374$ \\
\hline average age & 49.8 & 47.5 & 50.1 & 47.4 & 50.6 & 46.8 & 48.4 & 45.9 \\
\hline$\%$ adults in employment & 74.5 & 69.7 & 66.7 & 49.0 & 65.8 & 35.8 & 64.4 & 53.5 \\
\hline$\%$ secondary education & 35.09 & 36.82 & 39.9 & 40.0 & 58.8 & 54.5 & 71.5 & 72.1 \\
\hline$\%$ tertiary education & 29.57 & 30.24 & 33.1 & 21.8 & 7.3 & 6.0 & 22.2 & 22.7 \\
\hline$\%$ no children & \multicolumn{2}{|c|}{43.9} & \multicolumn{2}{|c|}{53.8} & \multicolumn{2}{|c|}{28.7} & \multicolumn{2}{|c|}{48.8} \\
\hline$\%$ one child & \multicolumn{2}{|c|}{22.2} & \multicolumn{2}{|c|}{20.5} & \multicolumn{2}{|c|}{27.6} & \multicolumn{2}{|c|}{20.2} \\
\hline$\%$ two children & \multicolumn{2}{|c|}{21.8} & \multicolumn{2}{|c|}{19.4} & \multicolumn{2}{|c|}{32.6} & \multicolumn{2}{|c|}{21.9} \\
\hline$\%$ three or more children & \multicolumn{2}{|c|}{12.1} & \multicolumn{2}{|c|}{6.3} & \multicolumn{2}{|c|}{11.1} & \multicolumn{2}{|c|}{9.2} \\
\hline
\end{tabular}

Source: Authors' calculations, based on EUROMOD 
Table 3: Average strategic weight by number of children

\begin{tabular}{lcc}
\cline { 2 - 3 } $\begin{array}{l}\text { Couples without } \\
\text { children }\end{array}$ & Finland & Germany \\
\cline { 2 - 3 } $\begin{array}{l}\text { Couples with children } \\
\text { One child }\end{array}$ & 0.958 & 0.936 \\
Two children & 0.928 & 0.857 \\
$\begin{array}{l}\text { Three or more } \\
\text { children }\end{array}$ & 0.911 & 0.822 \\
\hline & 0.889 & 0.739 \\
\cline { 2 - 2 } $\begin{array}{l}\text { Couples without } \\
\text { children }\end{array}$ & 1.022 & $\mathrm{UK}$ \\
\cline { 2 - 3 } $\begin{array}{l}\text { Couples with children } \\
\text { One child }\end{array}$ & 1.015 & 0.945 \\
$\begin{array}{l}\text { Two children } \\
\begin{array}{l}\text { Three or more } \\
\text { children }\end{array}\end{array}$ & 1.037 & 0.904 \\
\hline \hline
\end{tabular}

Source: Authors' calculations, based on EUROMOD

Table 4: Average strategic weight by female employment status (working-age households)

\begin{tabular}{lcc}
\cline { 2 - 3 } & Finland & Germany \\
\cline { 2 - 3 } & & \\
Couples without children & & \\
- female partner not in employment & 0.942 & 0.866 \\
- female partner in employment & 0.953 & 0.971 \\
Couples with children & & \\
- female partner not in employment & 0.818 & 0.745 \\
- female partner in employment & 0.927 & 0.869 \\
& & \\
\hline & & \\
\cline { 2 - 3 } & Italy \\
\cline { 2 - 3 } & & 0.881 \\
Couples without children & & 0.993 \\
- female partner not in employment & 1.035 & \\
- female partner in employment & 1.001 & 0.794 \\
Couples with children & & \\
- female partner not in employment & 1.085 & 0.918 \\
- female partner in employment & 0.977 & \\
\hline \hline
\end{tabular}

Source: Authors' calculations, based on EUROMOD 
Table 5: Normalised average strategic weight by female partner employment status and presence of children

\begin{tabular}{cccc}
\multicolumn{2}{c}{ Finland } & \multicolumn{2}{c}{ Germany } \\
\hline Male & Female & Male & Female \\
\hline
\end{tabular}

Couples without children

- female partner not in employment

- female partner in employment

0.638

0.362

0.712

0.288

Couples with children

- female partner not in employment

- female partner in employment

0.549

0.451

0.550

0.450

$\begin{array}{llll}0.557 & 0.443 & 0.478 & 0.522 \\ 0.505 & 0.495 & 0.456 & 0.544\end{array}$

Italy

United Kingdom

Male Female $\quad$ Male Female

Couples without children

- female partner not in employment

- female partner in employment

$\begin{array}{llll}0.817 & 0.183 & 0.785 & 0.215 \\ 0.525 & 0.475 & 0.566 & 0.434\end{array}$

Couples with children

- female partner not in employment

$\begin{array}{llll}0.759 & 0.241 & 0.655 & 0.345 \\ 0.518 & 0.482 & 0.521 & 0.479\end{array}$

- female partner in employment

0.518

0.521

0.479

Source: Authors' calculations, based on EUROMOD 
Table 6: Average impact of net transfers on standardised strategic weight (by number of children)

\begin{tabular}{|c|c|c|c|c|}
\hline & \multicolumn{2}{|c|}{ Finland } & \multicolumn{2}{|c|}{ Germany } \\
\hline & Male & Female & Male & Female \\
\hline No children & 0.574 & 0.426 & 0.631 & 0.369 \\
\hline Original income & 0.374 & 0.325 & 0.509 & 0.331 \\
\hline Transfers & 0.200 & 0.101 & 0.122 & 0.039 \\
\hline \% change & 53.554 & 31.058 & 23.919 & 11.717 \\
\hline One child & 0.525 & 0.475 & 0.515 & 0.485 \\
\hline Original income & 0.721 & 0.536 & 1.036 & 0.431 \\
\hline Transfers & -0.196 & -0.062 & -0.521 & 0.054 \\
\hline \% change & -27.158 & -11.466 & -50.259 & 12.564 \\
\hline Two children & 0.512 & 0.488 & 0.453 & 0.547 \\
\hline Original income & 0.793 & 0.497 & 1.240 & 0.386 \\
\hline Transfers & -0.281 & -0.009 & -0.787 & 0.161 \\
\hline \% change & -35.474 & -1.771 & -63.487 & 41.782 \\
\hline Three or more children & 0.473 & 0.527 & 0.326 & 0.674 \\
\hline Original income & 0.745 & 0.408 & 1.173 & 0.344 \\
\hline Transfers & -0.272 & 0.120 & -0.847 & 0.330 \\
\hline \multirow[t]{3}{*}{ \% change } & -36.552 & 29.317 & -72.195 & 95.860 \\
\hline & \multicolumn{2}{|c|}{ Italy } & \multicolumn{2}{|c|}{ United Kingdom } \\
\hline & Male & Female & Male & Female \\
\hline No children & 0.655 & 0.345 & 0.641 & 0.359 \\
\hline Original income & 0.373 & 0.206 & 0.612 & 0.332 \\
\hline Transfers & 0.282 & 0.138 & 0.029 & 0.026 \\
\hline \% change & 75.610 & 67.123 & 4.814 & 7.905 \\
\hline One child & 0.626 & 0.374 & 0.567 & 0.433 \\
\hline Original income & 0.665 & 0.393 & 0.826 & 0.432 \\
\hline Transfers & -0.039 & -0.019 & -0.258 & 0.000 \\
\hline \% change & -5.795 & -4.777 & -31.283 & 0.054 \\
\hline Two children & 0.645 & 0.355 & 0.583 & 0.417 \\
\hline Original income & 0.762 & 0.371 & 0.974 & 0.347 \\
\hline Transfers & -0.116 & -0.016 & -0.391 & 0.069 \\
\hline$\%$ change & -15.278 & -4.294 & -40.113 & 19.999 \\
\hline Three or more children & 0.632 & 0.368 & 0.522 & 0.478 \\
\hline Original income & 0.731 & 0.324 & 0.803 & 0.278 \\
\hline $\begin{array}{c}\text { Transfers } \\
\%\end{array}$ & -0.099 & 0.044 & -0.282 & 0.200 \\
\hline change & -13.586 & 13.681 & -35.062 & 72.037 \\
\hline
\end{tabular}

Source: Authors' calculations, based on EUROMOD 
Table 7: Average impact on individual strategic weight of different instruments, by income decile (households without children)

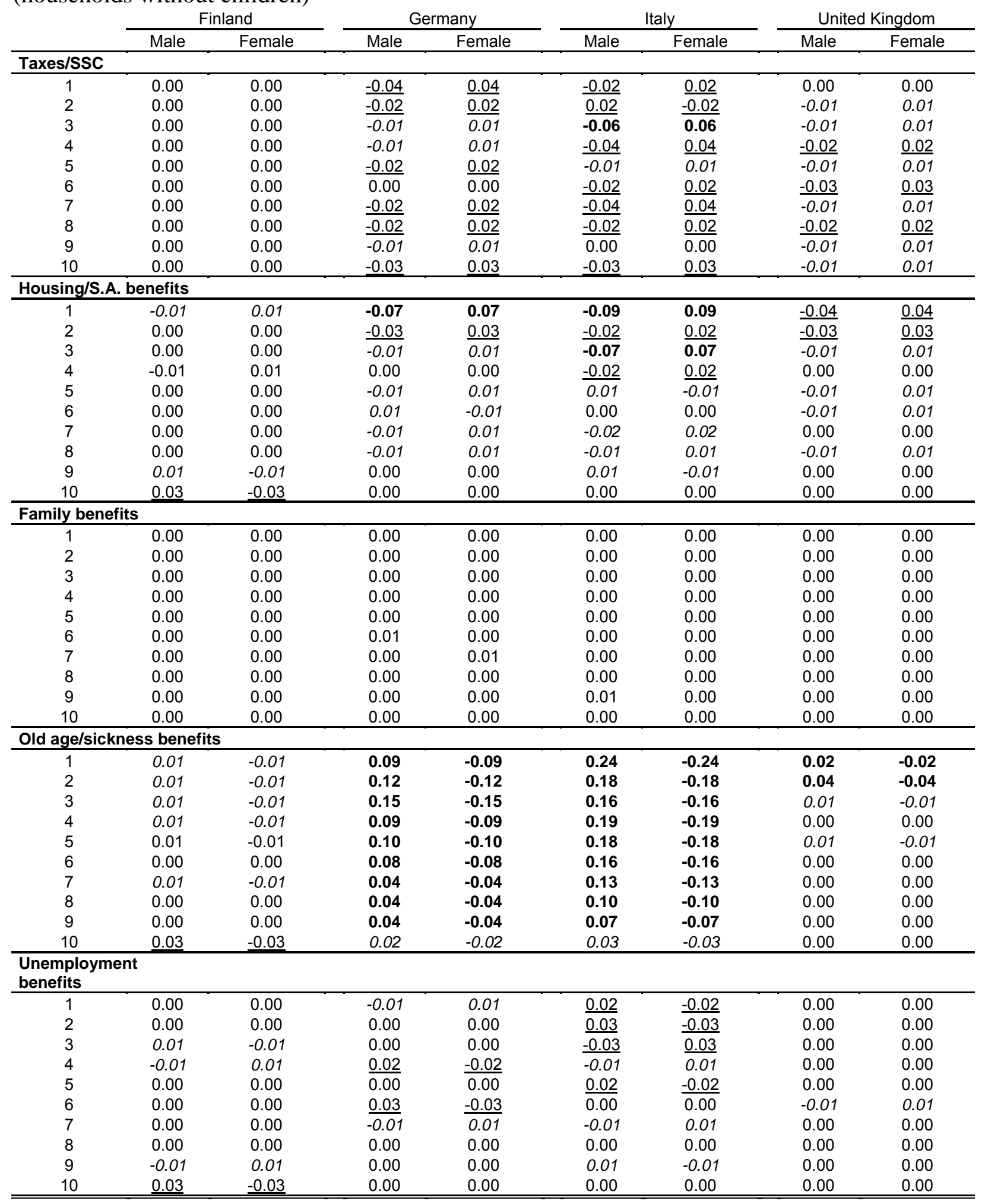

Note: Figures are in italics for absolute changes in the range $(0.0 .1]$, underlined for absolute changes in the range $(0.1,0.4]$ and in bold for absolute changes in the range $(0.4, \infty)$.

Source: Authors' calculations, based on EUROMOD 
Table 8: Average impact on individual strategic weight of different instruments, by income decile (households with children)

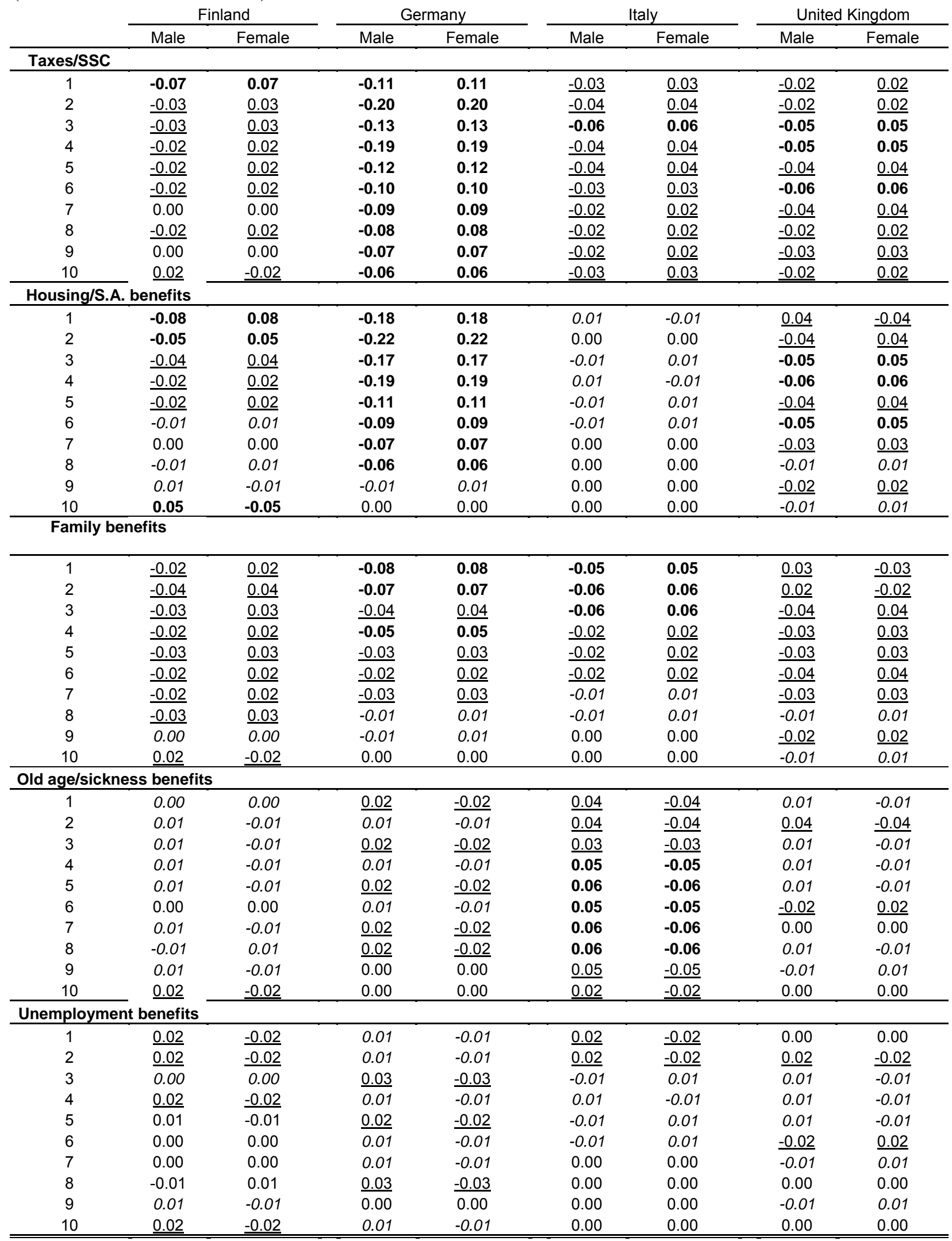

Note: Figures are in italics for absolute changes in the range $(0,0.1]$, underlined for absolute changes in the range $(0.1,0.4]$ and in bold for absolute changes in the range $(0.4, \infty)$.

Source: Authors' calculations, based on EUROMOD 
Fig. 1: Neutrality index by disposable income deciles (couples with and without children)
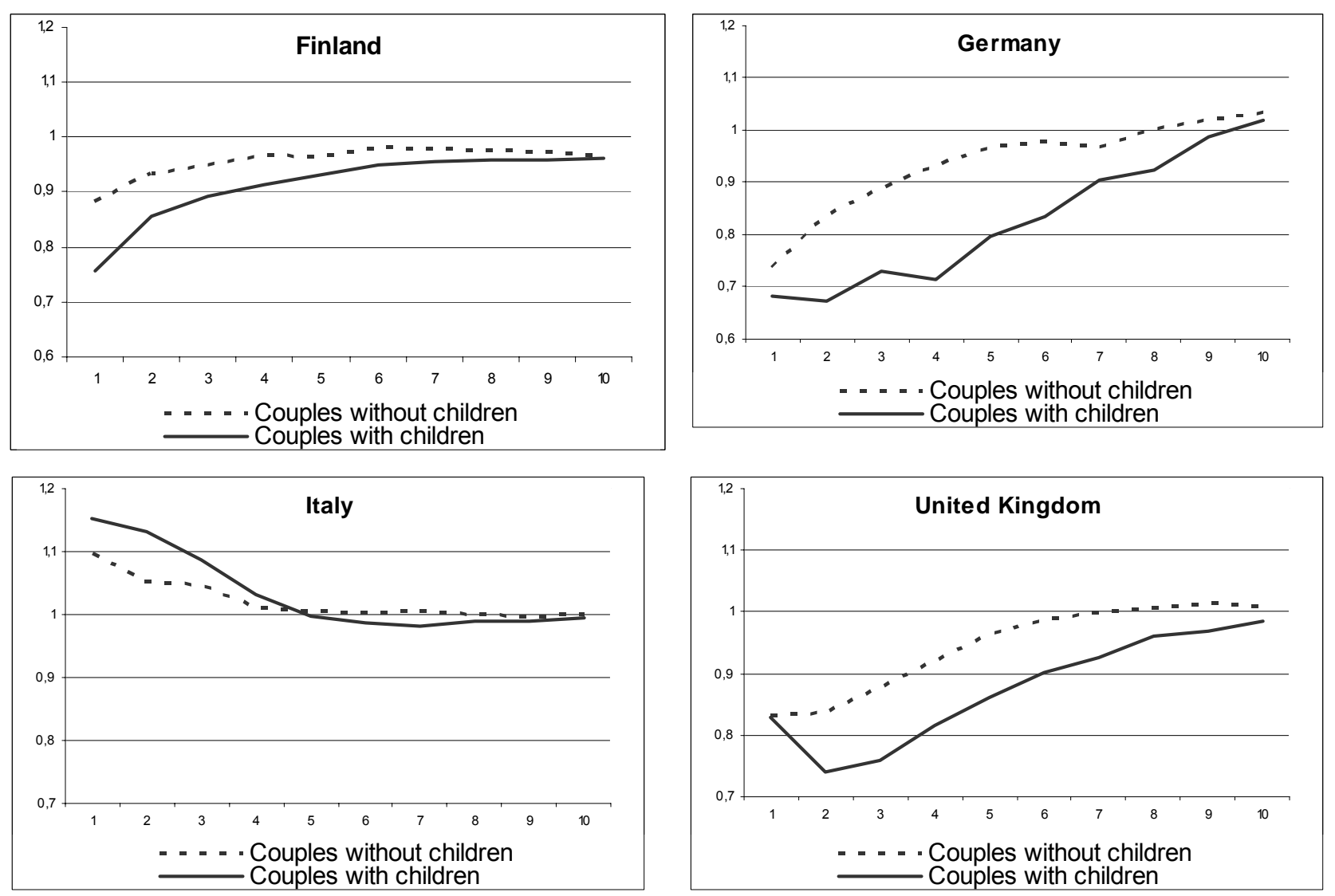
Fig. 2: Strategic weight by household disposable income decile (households without children)
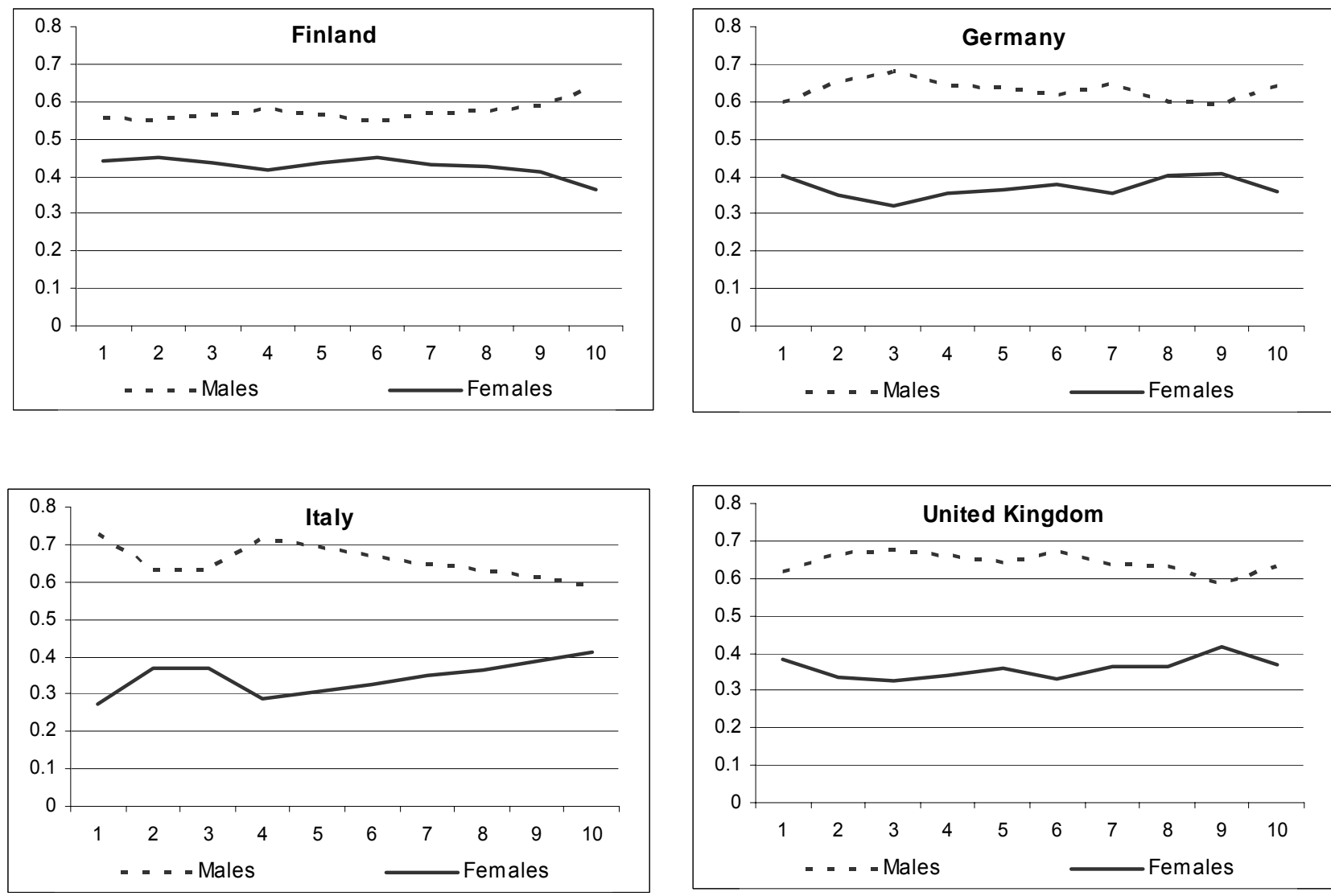

Fig. 3: Strategic weight by household disposable income decile (households with children)
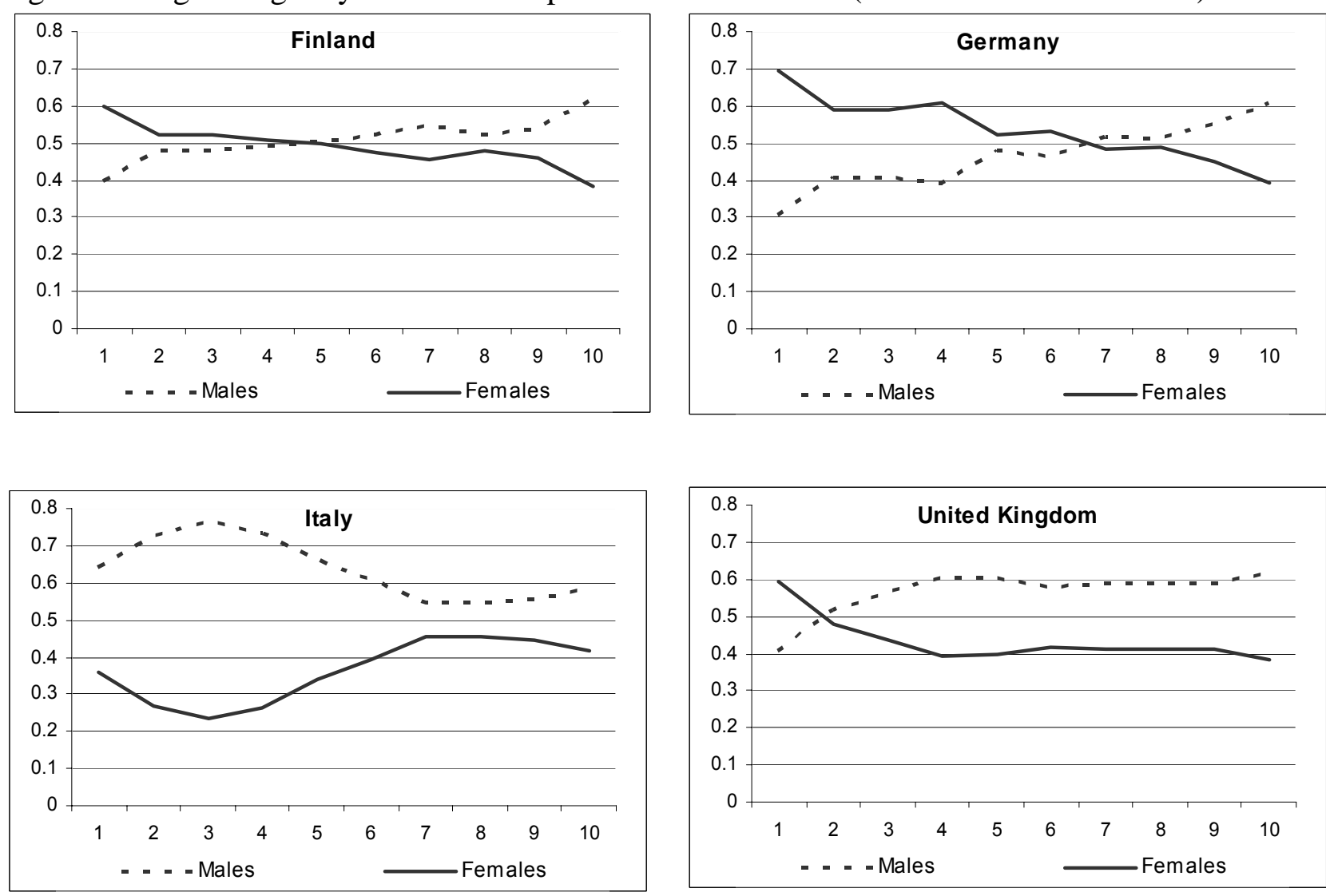
Fig.4: Strategic weights computed for gross market income and disposable income, by household disposable income decile (households without children)
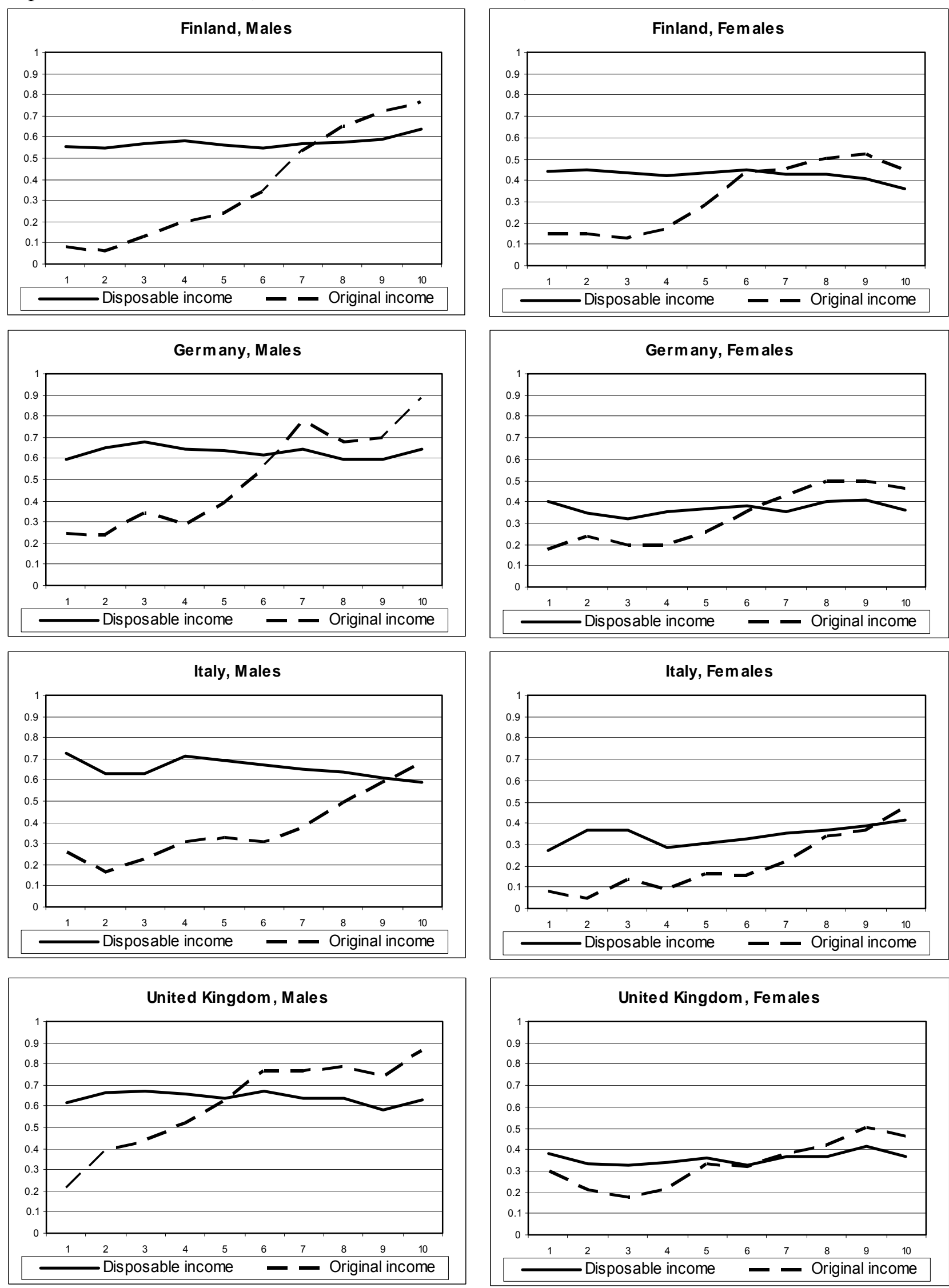
Fig. 5: Strategic weights computed for gross market income and disposable income, by household disposable income decile (households with children)
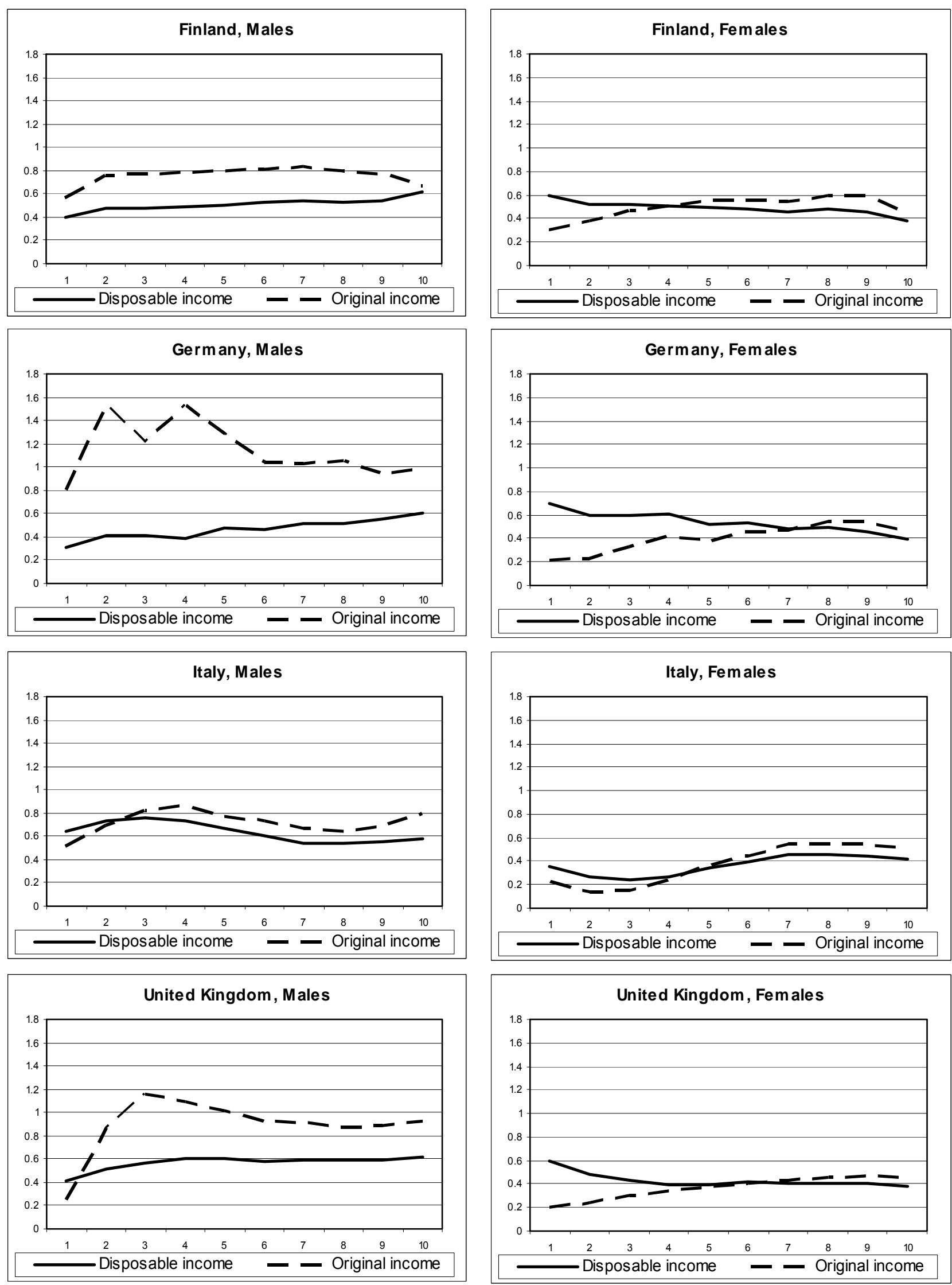